H. Q. Stevenson, And A. E. Keilr. 1958. Limits and consequences of multiple allopolyploidy in Nicotiana. The Nucleus 1: 205-222.

Swain, M. L., A. Eisner, C. F. Woodward, and B. A. BrICE. 1949. Ultraviolet absorption spectra of nicotine, nornicotine and some of their derivatives. Jour. Amer. Chem. Soc. 71 : 1341-1345.

Tso, T. C. 1962. Some novel concepts on the biosynthesis and biogenesis of tobacco alkaloids. Bot. Bull. Acad. Sinica 3: 61-71.

——, And R. N. Jeffrey, 1953. Paper chromatography of alkaloids and their transformation products in Maryland tobacco. Arch. Biochem. Biophys. 43: 269-285.

Turner, B. L., and R. Alston. 1959. Segregation and recombination of chemical constituents in a hybrid swarm of Baptisia laevicaulis $\times B$. viridis and their taxonomic implications. Amer. Jour. Bot. 46: 678-686.

WADA, E., T. KISAKI, AND M. InIDA. 1959. The tobacco alkaloids in the root and sap of some Nicotiana plants. Arch. Biochem. Biophys. 80: 258-267.

Willitts, C. O., M. L. Swain, J. A. Connellly, and B. A. BRICE. 1950. Spectrophotometric determination of nicotine. Anal. Chem. 22: 430-433.

\title{
TRACHEARY ELEMENTS OF THE FERNS. I. FACTORS WHICH INFLUENCE TRACHEID LENGTH; CORRELATION OF LENGTH WITH EVOLUTIONARY DIVERGENCE ${ }^{1}$
}

\author{
RICHARD A. WhiTE 2 \\ Department of Botany, University of Michigan, Ann Arbor, Michigan
}

\begin{abstract}
A B S T R A C T
Whiте, R. A. (U. Michigan, Ann Arbor.) Tracheary elements of the ferns. I. Factors which influence tracheid length; correlation of length with evolutionary divergence. Amer. Jour. Bot. 50(5): 447-455. 1963.-To determine the variability of tracheid lengths in ferns, several factors were surveyed which might modify them. On the basis of average lengths based on from 100 to 300 measurements, the following factors were found to affect fern tracheid length significantly: location in the plant, stage of maturation of the plant, length of the internode, ploidy, and habitat. These factors were considered when a statistical analysis was made of the relationship between tracheid length and taxonomic divergence among the species of ferns. A Pearson's correlation coefficient was computed, based on average tracheid lengths from 221 species of ferns, and a divergence index based on 8 characters accepted as indicators of specialization or primitiveness in the ferns. A statistically significant correlation (at the $5 \%$ level) between length and divergence was found for root tracheids, but not for rhizome or petiolar tracheids. A better understanding of fern evolution is necessary before a more precise picture of length correlation and divergence in the ferns can be obtained.
\end{abstract}

IDEAS of the evolutionary relationships of ferns are presently in a state of controversy and flux, and there are many differing views. The early classifications of Diels (1899), Bower (1923, 1926, 1928) and Christensen (1938) have been modified and revised by the more recent work of Ching (1940), Copeland (1947), and Holttum (1949).

\footnotetext{
${ }^{1}$ Received for publication August 15, 1962.

Part of a dissertation presented to the Horace H. Rackham School of Graduate Studies, University of Michigan, in partial fulfillment of the requirements for the degree of Doctor of Philosophy. The advice and assistance of Dr. Paul S. Dwyer, Mathematies Dept. and Statistical Laboratory of the University of Michigan, with the statistical portions of this study, and of Drs. Charles B. Beck and Warren H. Wagner, Jr., throughout the course of thi work is gratefully acknowledged. Opportunities to collect research materials were made possible by an $\mathrm{H}$. H. Rackham School Summer Grant, The H. H. Bartlett Fund and N.S.F. Grant G-10846.

${ }_{2}$ The author is presently $(1962-63)$ a National Science Foundation Postdoctoral Fellow in Botany at the University of Manchester, England.
}

These later workers have incorporated numerous morphological characters into their systems in an attempt to determine more accurately the relationships in this group. The fact that there are such differing views, however, indicates a need for additional characters of comparative value which can be used in correlation with those already known.

Problems of evolutionary relationships in the angiosperms have been approached frequently through the use of comparative anatomical data (Bailey, 1949). Studies of the xylem have been one of the chief sources of information regarding trends of diversification within the higher groups. The works of Bailey and Tupper (1918), Frost (1930a, b), and Cheadle (1943) are major attempts to determine morphological trends in xylem elements which can be applied to the broader problems of evolution in those groups studied. Their conclusions have had a far-reaching effect on our understanding of the systematies of the flowering plants. 
TABLE 1. Comparison of average lengths of tracheids from long and short internodes. Both examples indicate a relationship between tracheid length and internode length.

\begin{tabular}{|c|c|c|c|c|c|c|}
\hline \multirow{2}{*}{\multicolumn{2}{|c|}{$\begin{array}{c}\text { Matteucia struthiopteris } \\
\text { (Aspidiaceae) }\end{array}$}} & & \multicolumn{4}{|c|}{$\begin{array}{l}\text { Nephrolepis spp. } \\
\text { (Davalliaceae) }\end{array}$} \\
\hline & & & \multicolumn{2}{|c|}{$N$. cordifolia } & \multicolumn{2}{|c|}{ N. hirsutula } \\
\hline & & S.D. & & S.D. & & S.D. \\
\hline \multicolumn{7}{|l|}{ Rhizome } \\
\hline erect & 1.21 & 0.17 & 2.30 & 0.22 & 1.63 & 0.49 \\
\hline procumbent & 5.46 & 1.78 & 6.42 & 1.84 & 3.22 & 1.00 \\
\hline Root & 3.52 & 1.00 & 1.79 & 0.23 & - & \\
\hline Petiole & 2.86 & 0.74 & 5.64 & 1.59 & 9.54 & 2.19 \\
\hline
\end{tabular}

. Tracheid length in $\mathrm{mm}$.

In contrast to this extensive work on xylary tissue in the angiosperms, nothing of a similar scope has heretofore been done for the ferns. It would be valuable to know whether the evolutionary patterns described for tracheids and vessel members of the higher groups are also present in the ferns. Whether or not such trends are found, a broader knowledge of the variation of the morphology of the tracheary elements of the ferns might provide additional information of systematic and evolutionary significance.

A primary aim of this research, therefore, was to compare the variation in morphology of tracheary cells over a wide sample of fern species. All of the relevant characters regarded as significant by Bailey and Tupper (1918), Frost (1930a, b), and Tippo (1946) were examined. A primary requirement, according to Frost (1930a), for a comparative study from which broad evolutionary trends are to be established is the presence of sufficient diversity in the character to be used as the basis for conclusions. The discovery of vessels in the roots of Marsilea (White, 1961) and presence of tracheids which are morphologically intermediate between vessel members and tracheids in widely separated genera of ferns, to be described subsequently, scem to satisfy this requirement.

In order to ascribe comparative value to any trends which may be found in tracheid length and morphology in the forns, one must consider factors which affect these features. Those conditions that are induced by external influences are of less value than those which are genetic in nature. Previous studies of gymnosperms and angiosperms have revealed the presence of several genetic, environmental, and positional factors which modify tracheid length.

A single pattern of length variation which is uniformly applicable to plants in general has not yet been established.

Most workers studying the normal variation of cells and tissues have utilized the secondary xylem of woody plants in which cambial initials play an important role in the establishment of tracheid length. The only recent comparative studies of primary xylem have been made by Cheadle (1943) and Bierhorst (1960), and no studies have been made of the variation patterns in the length of fern tracheids.

Materials AND METHODS-The materials used in this study of ca. 210 species in approximately 91 genera and 18 families were made available to me by Mr. A. Murray Evans, Professor Warren H. Wagner, Jr., Professor Ralph H. Wetmore, Mr. Wing Yew Kwan, Miss Anne Johnson, the University of Michigan Herbarium, and the University of Michigan Botanical Gardens. Personal collections were made in the Hawaiian Islands in the summer of 1961. Vouchers have been maintained for most of this work.

Both dried and fixed specimens were used. Where sections were made, the killing and fixing were followed by dehydration in a tertiary butyl alcohol series and embedding in paraffin, as described by Johansen (1940). Serial longitudinal and transverse sections were cut $(10 \mu)$ and stained with a combination of safranin and fast green.

For maceration, the technique of Jeffrey (1917) was found to be the most useful. Better results were obtained with dried material if it was pretreated in an aqueous solution of Tergitol prior to maceration. A $1 \%$ solution of Bismark Brown in $70 \%$ alcohol was used as the stain.

Where possible, 100 tracheids each were measured from the rhizome, root, and petiole of each species. In evaluating the results of these observations, the mean and standard deviation were calculated. An ocular micrometer was uscd to measure tracheids chosen randomly from each slide. The maceration slide preparation technique was developed to the point where there was little breakage of tracheids during the process; hence a normal representation of both larger and shorter tracheids was assured. The frequency distribution of tracheids in the samples (i.e., slides) approximated a normal curve.

A Pearson's correlation coefficient was computed (Dixon and Massey, 1957) to measure the extent of linear relationship between the degree of "relative divergence" of the family and the average tracheid length. The family index number was applied to the genera and species which make up each family, in order to compute the correlation coefficient at these levels. Specific collection data, 
TABLE 2. General decrease in average tracheid length" in successively older plants. Stages from A-C represent very young to older plants. Stage $D$ is an adult plant. See text for further explanation

\begin{tabular}{ccccccc}
\hline \hline & & \multicolumn{2}{c}{ Osmunda cinnamomea (Osmundacene) } & & \\
& Rhizome & S.D. & Root & S.D. & Petiole & S.D. \\
\hline A & 1.96 & 0.52 & 7.72 & 0.58 & - & \\
B & 1.64 & 0.45 & 6.36 & 0.62 & 5.94 & 1.77 \\
C & 1.70 & 0.40 & 5.36 & 0.58 & 4.80 & 1.37 \\
D & 1.14 & 0.40 & 1.54 & 0.62 & 2.40 & 0.98 \\
\hline
\end{tabular}

a Tracheid length in $\mathrm{mm}$.

and individual measurements for this survey are on deposit as a thesis at the University of Michigan.

Results-Organographic location-Measurements were made of tracheid lengths in the rhizome, root, and petiole of 125 species of ferns. The results reveal no simple correlation between tracheid length and the organ in which they oceur. Although the rhizome tracheids were the shortest in $77 \%$ of the species studied, they were the longest elements in $10 \%$ and intermediate between those of the petiole and root in $13 \%$ of the species examined. In contrast, the root contained the longest tracheids in $35 \%$, tracheids of intermediate length in $45 \%$, and the shortest elements in $20 \%$ of the species studied. The petiolar tracheids were longest in $55 \%$, intermediate in $42 \%$ and shortest in only $3 \%$ of the species examined. In general, tracheids in the rhizomes were shorter in mean length than those in either the petiole or the root, while those of the petiole were the longest in the plant in almost $60 \%$ of the species studied.

Internode length-In view of the effects of lateral branches and internode length on tracheid length in higher plants, the relationship of internode length to tracheid length in the ferns was studied. An attempt was made to predict internode length on the basis of average lengths of rhizome tracheids of 50 species of Aspidiaceae. The internode length predictions in terms of "creeping" vs. "upright" rhizomes, when compared with taxonomic descriptions of the species (Copeland, 1947; Holttum, 1954; Wherry, 1961) proved to be almost $100 \%$ accurate. Additional species were reviewed in this manner, and internode length of most of the species could be predicted.

This relationship between internode length and tracheid length was confirmed by studying the rhizome tracheids of Matteucia struthiopteris (Aspidiaceae) and Nephrolepis cordifolia and N.hirsutula (Davalliaceae). In all 3 species there is an erect rhizome with short internodes, from which arise either stoloniferous rhizomes (Nephrolepis spp.) or creeping rhizomes (Matteucia) with long internodes in both cases. Comparison of average lengths of tracheids in the 2 types of rhizomes (Table 1) reveals a positive relationship between the length of the internode and the length of the tracheids. Irom these results it was concluded that the length of tracheids in fern rhizomes is related to the internode length of the species.

Stage of maturity of the plant - Since the length of tracheids may depend on the developmental stage of the plant or organ in which the tracheids occur, a series of plants, of varying ages or stages of maturity, was collected of Osmunda cinnamomea (Osmundaceae). Comparison of mean tracheid lengths indicated that in progressively more mature developmental stages there is a general shortening of the elements in all 3 organs (Table 2). This trend is most elear in the petiole and root, where the average length of the tracheids is shorter in each successively older plant. The relationship of tracheid length to organ is also modified during the development from juvenile to adult plant. In the younger stages of Osmunda, the longest tracheids were in the root, not in the petiole; whereas the longest trachcids in the adult plant were in the petiole.

Ploidal level-Average tracheid length was determined in diploid species, polyploid species and known or probable hybrids of Botrychium (Ophioglossaceae), Asplonium (Aspleniaceac) and Dryopteris (Aspidiaccac).

The results of the study of Botrychium (Table 3 ) indicate that ploidal level and cell size are correlated: with an increase in ploidal level, there is an increase in average tracheid length. Tracheids of the $2 x$ species, B.lunaria of section Botrychium, are shorter than those of the $4 x$ species, B.minganense. Botrychium alabamense (of section Sceptridium) is the putative amphidiploid hybrid between B.biternatum and B.lunarioides (Wagner, $1962)$. The first parent, B.biternatum $(2 x)$ has an average length of $2.26 \mathrm{~mm}$, the second of $1.44 \mathrm{~mm}$, and the hybrid, B.alabamense, has an average of $1.70 \mathrm{~mm}$. The genome contributed by B.lunarioides modifies the tracheid length of the hybrid to a greater degree than that of B.biternatum. This results in tracheids of intermediate length which, even though in a $4 x$ plant, are smaller $(1.70 \mathrm{~mm})$ than those of the presumed $2 x$ parent, B.biternatum. This pattern of inheritance is known also in pollen grains of grasses (Gould, 1957), and in tracheids of pine (Echols, 1955; Jackson and Greene, 1958).

A series of plants of different polyploid levels in the Asplenium heterochroum complex growing 
TABLE 3. Relationship between tracheid length and ploidal level. Data indicate an increase in average tracheid length with an increase in ploidal level

\begin{tabular}{|c|c|c|c|}
\hline $\begin{array}{l}\text { Chromo- } \\
\text { some } \\
\text { number }\end{array}$ & Species & $\begin{array}{l}\text { Tracheid } \\
\text { length } \\
\text { (in } \mathrm{mm} \text { ) }\end{array}$ & S.D. \\
\hline \multicolumn{4}{|c|}{ Botrychium } \\
\hline & \multicolumn{3}{|l|}{ Sect. Sceptridium } \\
\hline $2 x$ & $\begin{array}{l}\text { B. biternatum } \\
\quad(\text { syn. B. tenuifolium) }\end{array}$ & 2.26 & 0.93 \\
\hline $2 x$ & B. lunarioides & 1.44 & 0.35 \\
\hline \multirow[t]{2}{*}{$4 x$} & B. alabamense & 1.70 & 0.27 \\
\hline & \multicolumn{3}{|l|}{ Sect. Botrychium } \\
\hline $2 x$ & B. lunaria & 1.12 & 0.27 \\
\hline \multirow[t]{2}{*}{$4 x$} & B. minganense & 1.67 & 0.45 \\
\hline & \multicolumn{3}{|l|}{ Asplenium } \\
\hline $2 x$ & $\begin{array}{l}\text { A. heterochroum } \\
\text { (presumed diploid) }\end{array}$ & 2.04 & 0.50 \\
\hline $4 x$ & A. heterochroum & 2.12 & 0.57 \\
\hline $3 x$ (apog) & A. resiliens & 3.38 & 0.82 \\
\hline $6 x$ & A. heterochroum & 4.76 & 0.70 \\
\hline \multirow[t]{3}{*}{$5 x($ apog $)$} & A. heterochroum $(2 x)$ & 3.94 & 0.88 \\
\hline & $\times$ & & \\
\hline & A. resiliens $(3 x)$ & & \\
\hline
\end{tabular}

under the same environmental conditions at the University of Michigan Botanical Gardens was studied. Chromosome counts of all the species had been recently made (Morzenti and Wagner, 1962). Within this series also (Table 3), there is a positive relationship between increase in ploidal level and increase in tracheid length. An apogamous species, A.resilicns (3x), however, had longer tracheids than either the $2 x$ or $4 x$ A.heterochroum. The average length $(3.94 \mathrm{~mm})$ of the $5 x$ apogamous hybrids A.heterochroum $\times$ resiliens is larger than that of either of its parents, but fits into the length series of the A.heterochroum species.

A more thorough investigation was made of a polyploid series involving hybridization in Dryopteris. The specimens used all grew in a uniform natural community in Washtenaw County, Michigan. The tracheids of 3 species and the hybrids between them were measured. Comparative results again reveal a positive relationship between ploidal level and tracheid length (Table 4).

Tracheids from all 3 organs were measured to determine whether location in the plant affects the expression of the genetic correlation. The results of measurements in the rhizome seem to indicate that D.goldiana $(2 x)$ has a "long tracheid" trait in contrast to a "short tracheid" trait in $D$. cristata $(4 x)$. Since this relationship is not true of tracheids from the petiole and root in the same plants, however, the rhizome tracheid lengths can perhaps be ascribed to differences in internode length in the 2 species rather than differences in ploidal level. The fertile presumed allotetraploid, D. $\times$ clintoniana $(6 x)$ (Walker, 1961), has tracheids which are longer than those of either the
$2 x, 4 x$, or $5 x$ taxa. The $5 x$ backcross, D.clintoniana $\times$ cristata, does not have rhizome tracheids of intermediate length between the parents, but the rhizome tracheids of the other backcross, $D$. clintoniana $\times$ goldiana, are intermediate in length.

In the root, the situation is reversed. Tracheid length of the hybrid D.clintoniana $\times$ goldiana $(4 x)$ is intermediate, but that of the hybrid D.clintoniana $\times$ cristata $(5 x)$ is not. In the latter hybrid, tracheid length is actually greater than in one of the parents $(6 x)$.

No material of the rhizome and root of the scarce sterile diploid of the hybrid D.cristata $\times$ goldiana was available.

In the petiole (Table 4), there is an increase in average tracheid length from those species with low ploidal levels to those with high. Tracheids in the petiole of the hybrids $D$.clintoniana $\times$ cristata, D.clintoniana $\times$ goldiana and D.cristata $\times$ gold iana are of a length intermediate between that of their parents. Also, the fertile allopolyploid $D . \times$ clintoniana $(6 x)$ shows an increase in average tracheid length over its sterile $3 x$ form, D.cristata $\times$ goldiana.

The tracheids of both the root and petiole are longer than those of the rhizome, but the relationship between the lengths of tracheids in the root and petiole varied with each species.

These studies in 3 different fern families demonstrate that the length of tracheids is genetically controlled and there is, in general, a positive relationship between ploidal level and tracheid length.

'TABLE 4. Relationship between hybrid origin of species and tracheid length in Dryopteris. Hybrid species tend to have tracheids which are intermediate in length between those of parent species

\begin{tabular}{lcc}
\hline \multicolumn{1}{c}{ Organ } & $\begin{array}{c}\text { Tracheid } \\
\text { length } \\
\text { (in mm) }\end{array}$ & \\
& & \\
\hline & & \\
\hline Rhizome & 1.70 & 0.38 \\
$D$. goldiana $(2 x)$ & 1.81 & 0.40 \\
D. clintoniana $(6 x)$ & 1.76 & 0.33 \\
D. clintoniana $\times$ goldiana $(4 x)$ & 1.44 & 0.36 \\
D. cristata $(4 x)$ & 1.55 & 0.38 \\
D. clintoniana $\times$ cristata $(5 x)$ & & \\
Root & 4.00 & 0.85 \\
D. goldiana $(2 x)$ & 5.50 & 1.39 \\
D. clintoniana $(6 x)$ & 4.96 & 1.10 \\
D. clintoniana $\times$ goldiana $(4 x)$ & 4.18 & 1.39 \\
D. cristata $(4 x)$ & 5.64 & 1.39 \\
D. clintoniana $\times$ cristata $(5 x)$ & & \\
Petiole & 3.50 & 0.77 \\
D. goldiana $(2 x)$ & 5.50 & 1.79 \\
D. clintoniana $(6 x)$ & 4.50 & 1.37 \\
D. clintoniana $\times$ goldiana $(4 x)$ & 5.83 & 1.75 \\
D. cristata $(4 x)$ & 4.27 & 1.17 \\
D. cristata $\times$ goldiana $(3 x)$ & 5.60 & 1.75 \\
D. clintoniana $\times$ cristata $(5 x)$ & & \\
\hline
\end{tabular}


Ecological variation-Four local species in S. E. Michigan, Onoclea sensibilis, Thelypteris palustris, Woodsia ilvensis (Aspidiaceac) and Pteridium aquilinum (Pteridaceae), were studied for the effects of "dry-exposed" (i.e., in open fields) and "moistshaded" (i.e., in more or less closed swamp woods) environment on tracheid lengths. Several specimens of each species were collected from each of the 2 contrasting environments. $+10$

Measurements of tracheids from the roots and petioles of the first 3 species revealed that the plants from dry-exposed habitats tend to have shorter, narrower tracheids than those of the moist-shaded habitats ('Table 5). Tracheary elements of all organs of Pteridium and the rhizome tracheids of other species, however, indicate the opposite result, with tracheids from the plants in dry-exposed habitat longer and in some cases wider than those from plants in the moist habitat. In regard to Pteridium it is noteworthy that Boodle (1904) found an increase of laminar cell size in plants growing in sunlight in comparison with those growing in shade.

Statistical analysis-In the higher vascular plants, it is gencrally accepted that long, tapered tracheids are primitive in contrast to shorter, more highly modified water-conducting cells (Tippo, 1946). A review of the measurements presented by Bailey and Tupper (1918) shows that, in general, there is a trend of shortening of tracheids from the fossil species they studied through the gymnosperms to the angiosperms. There are numerous exceptions to this trend among their data, however, and in view of the plant diversity which their survey encompassed, this is not surprising. From a similar review of the measurements obtained in the present survey of the ferns (White, 1962 ) it is not immediately apparent that such a pattern of tracheid shortening with evolutionary divergence is present. In order to determine the degree of correlation, if any, between the probable cvolutionary level of a particular species and the average length of its tracheids, a statistical study was made.

In the survey of tracheary lengths which follows, the location of the tracheids in the plant, the age of the plant, and, to a limited extent, the environment in which the plant was growing were taken into account.

In view of the complicating factor of internode length in the rhizome, most of the species were sampled in the root and the petiole as well. Average lengths based on measurements of between 100 and 300 late metaxylem tracheids were obtained from each organ of each species. As suggested by numerous previous studies which include tracheid measurements, the average measurements and standard deviations were determined so that the extent of variation in the material could be seen.

A combination of the most commonly accepted families of Copeland (1947) and Holttum (1949) was taken as the basis for comparisons. Divergence 
TABLE 6. Correlation coefficients, confidence intervals: for tracheids of rhizome, root and petiole. Results significant at $5 \%$ level indicated by*

\begin{tabular}{|c|c|c|c|}
\hline Organ & $\begin{array}{l}\text { No. of } \\
\text { Observations } \\
\text { (N) }\end{array}$ & $\begin{array}{c}\text { Correlation } \\
\text { coefficient } \\
\text { (r) }\end{array}$ & $\begin{array}{c}95 \% \\
\text { Confidence } \\
\text { interval }\end{array}$ \\
\hline \multicolumn{4}{|l|}{ Root } \\
\hline Family & 17 & -0.37 & $-0.72<r<-0.15$ \\
\hline Genus & 71 & -0.34 & $-0.52<\mathrm{r}<-0.12^{*}$ \\
\hline Species & 122 & -0.21 & $-0.37<\mathrm{r}<-0.04^{*}$ \\
\hline \multicolumn{4}{|l|}{ Rhizome } \\
\hline Family & 18 & -0.39 & $-0.73<r<+0.10$ \\
\hline Genus & 78 & 0.09 & $-0.13<r<+0.31$ \\
\hline Species & 173 & 0.21 & $0.05<r<+0.36$ \\
\hline \multicolumn{4}{|l|}{ Petiole } \\
\hline Family & 17 & -0.22 & $-0.64<r<+0.30$ \\
\hline Genus & 78 & -0.18 & $-0.38<\mathrm{r}<+0.04$ \\
\hline Species & 130 & -0.097 & $-0.28<\mathrm{r}<+0.08$ \\
\hline
\end{tabular}

indices (Wagner, 1961) were determined for them through the use of 8 characters generally acknowledged to be of systematic value in the ferns (Wagner, 1954). Those included in this study are as follows: (1) habitat-terrestrial mesophyte, primitive; epiphyte or hydrophyte, advanced; (2) spore morphology-tetrahedral spore without perispore, primitive; bilateral spore with perispore, advanced; (3) gametophyte-flat, bisexual, green gametophy te, primitive; filamentous, unisexual or heterotrophic gametophyte, advanced; (4) gametangia - many-celled gametangia, primitive; small, fewer-celled ones, advanced; (5) venation-free veins primitive; anastomosing veins advanced; (6) dermal trichomes-hairs primitive; palcae or scales advanced; (7) sporangia-large many-celled sporangia with no clearly defined anmulus, primitive; small, few-celled sporangia with clearly defined annulus, advanced; (8) soral maturationall sporangia mature simultaneously, primitive; mixed sori, advanced.

A total divergence index was estimated by giving one point to the family for each advanced character present in the family. Where a character was considered intermediate between the advanced and primitive state, one-half point was given for that character.

The results of the analysis of each of the 3 organs at the level of species, genus and family are summarized in Table 6 . In addition to the correlation coefficient, a $95 \%$ confidence interval was calculated. That is to say, in 95 out of 100 cases we would be correct in inferring that the confidence interval includes the population value (rho) (Table 6).

Essentially, the results reveal a significent correlation $\langle 0.26<$ rho $<0.52, \mathrm{p}<0.05)$ between tracheid length in the root and relative total divergence (advancement) of the family. Contrarily, there was an expected lack of a relationship between length and advancement in the rhizome. This latter discrepancy is probably related to the influence of the internode length of the rhizome on tracheid length. The lack of significant results in the petiole was not expected, however.

The statistical calculations for tracheids in the rhizome and petiole indicate that the correlation coefficient is not significant at the $5 \%$ level. On the basis of these data, the null hypothesis, that there is no correlation between relative advancement (divergence) and tracheid length, is accepted. It is still not possible, on the basis of these data, to say that there is no correlation in the population, only that there is not enough evidence using the sample data to reject the null hypothesis. The root measurement results indicate, however, that at the $5 \%$ level the null hypothesis is rejected. A correlation coefficient as large in absolute value as that obtained for roots $(-0.37<$ rho $<-0.04$ and $-0.52<$ rho $<-0.12$ ) would occur by chance 5 times in one hundred if no correlation were present in the population. Therefore, in the root, families with the highest index number (specialized) tend to have shorter tracheids than those with a lower index number (primitive). There are some indications that additional data may strengthen the correlations in all categories.

Discussion- On the basis of this investigation, one may conclude that variation in the length of fern tracheids is influenced to some degree by the following factors: (1) location of tracheids in the plant (i.e., whether from rhizome, root or petiole); (2) length of internodes in the rhizome; (3) the stage of maturation of the plant or organ (i.e., juvenile vs. adult); (4) the genetic constitution of the plant; (5) polyploid increases among members of the same or closely related species; and (6) habitat.

The petiole and root have, in general, longer tracheids than the rhizome. Length of rhizome tracheids is correlated more closely with internode length than with any of the other factors studied. In contrast to the close relationship found between internode length and tracheid length 
(Table 1), there was little correlation between ploidal level and length of tracheids in the rhizome. Tracheids from the stems of Osmunda plants of varying ages (Table 2) showed less change in length with an increase in age than those from the petiole or the root, and, except in Pteridium, rhizome tracheids were also the least modified by differences in the environment of the plant. From these data, it would appear that the systematic reliability of tracheid length in petioles and roots is altered most by ploidal level, stage of plant maturity, and conditions of the environment. The rhizome tracheids, on the contrary, are less affected by these factors. This does not make the rhizome any more dependable, however, because of the fact that internode length influences tracheid length, and different species of the same genus may differ from one another greatly in rhizome habit (i.e., creeping or erect). As Bailey (1957) and Carlquist (1958, 1959, 1960a, b) pointed out, those attributes which depend on plant habit are of relatively little value in determining trends of taxonomic significance.

The families which are considered primitive on the basis of numerous taxonomic characters show a pattern of tracheid Iength distribution according to organ, which is different from that in advanced families of the leptosporangiate types. The species of Osmundaceae, Cyatheaceae, Schizaeaceae and Gleicheniaceae all have the longest tracheids in the petiole, the shortest ones in the rhizome, and tracheids of in $\mathrm{e}^{-}$mediate length in the root. In contrast to this pattern, there is a more eomplex pattern in the advanced families. Species of the Pteridaceae, Adiantaceac, and Polypodiaceae may have the longest tracheids in either the petiole or the root, although the shortest tracheids are still usually in the rhizome. The eusporangiate Ophioglossaceae and Marattiaceae show a pattern similar to that of the more primitive leptosporangiate.

Measurements of tracheids from plants of different ages showed that there were differences between the average lengths in juvenile plants and those from adult plants. It is difficult to explain this shortening of the tracheids in organs of suecessively more mature plants.

Bissett and Dadswell (1950) found that the early-formed tracheids of gymnosperms (which grew under optimal conditions of light and moisture) are longer than the later-formed tracheids. A similar situation may exist in fern tracheid development. It is also possible that as organs become increasingly larger, and composed of more cells, there is a mean decrease in the size of cells composing the organs as suggested by Sierp (1914). Whatever the explanation for this decrease in size, the tracheids in all the organs of the adult plants are shorter than those in juvenile plants.

This study shows that a relationship also exists in the ferns between ploidal level and tracheid length. An increase in average tracheid length with an increase in chromosome number was described for different species of genera Botrychium, Asplenium, and Dryopteris, in 3 families. On the basis of this kind of information, one should be able to predict the comparative ploidal level in closely related plants. Such information might be particularly important in comparative anatomical studies at the genus and species level.

Tracheid lengths tend to increase with polyploidal increases in the same or very closely related species. In Asplenium heterochroum (Table 3), there is a general increase in tracheid length concomitant with increase in number of genomes in the species. The presumed diploid $(2 x)$ has the smallest average tracheid length, the tetraploid $(4 x)$ has longer tracheids than the $2 x$, but shorter tracheids than the hexaploid $(6 x)$. It is also apparent from these data that tracheid length is inherited in accordance with the origin of the genomes in the plant. The tracheids of the $5 x$ (apogamous) presumed hybrid between Asplenium heterochroum and A.resiliens, for example, have a mean length which is longer than either of the parents. If the tracheids in the hybrid $(5 x)$ are considered to be controlled by 3 "long tracheid factors" from A.resiliens, and 2 "short tracheid factors" from A.heterochroum, the additive effect would result in tracheids longer than those of the parents. Additional support for this correlation between tracheid length and genome constitution of the species is found in Dryopteris (Table 4). In each of the hybrid taxa, the tracheids are intermediate in mean length between those of the parents. This is true of petiolar tracheids in all of the hybrids and of all the root tracheids except those in the 5x Dryoptoris clintoniana $\times$ cristata.

The increase in tracheid length is never directly proportional to the increase in chromosome number, regardless of the manner by which the chromosome number is increased.

It would be unreasonable to ascribe primitiveness to tracheid length increase correlated with an increase in ploidal level since, in all probability, plodial increases indicate divergence rather than primitiveness within a given genus.

The length of tracheids also seems to be affected by the environment. Except in Pteridium (all organs) and the rhizome of the other genera studied, tracheids from plants which grow in a dry habitat are shorter than those from plants from moist habitats. The presence of tracheids in rhizomes of species growing in dry habitats that are longer than those from the same species from moist habitats does not conform to the results from other organs, or with previous reports in the literature. The ecological niche in which the plants normally grow offers no clue to an explanation of these unexpected results. A number of possibilities such as lack of canopy cover during early rhizome development, increased transpiration rate in the open, etc., suggest themselves as possible explanations for the differences in lengths of 
tracheids from comparable organs from the 2 different habitats. These factors do not, however, suggest any reasons for the difference in the direction of change in tracheids of the rhizomes from that of tracheids in the other 2 organs.

It is, nevertheless, apparent from these results that changes in length are brought about by differences in environment, and that the direction of change may not be consistent throughout the entire plant.

It is quite possible, therefore, that a character such as tracheid length may not be of use in determining evolutionary trends among species in a closely related group. In such studies, where the spectrum of variation in a given character is limited, the length of tracheids of closely related species may vary greatly becausc of environmental influences, whereas the length of those of distantly related species, growing in similar environments, may be very similar.

Unless an intensive study is made of the plants, it may be difficult to separate environmentally induced variations from those which are genetically determined, and hence possibly usetul for evolutionary comparisons. This variable may be minimized in a broad comparative study by increasing the size of the random sample, and by growing critical taxa under uniform conditions.

This problem is less critical when the study is a broad investigation in which there is considerable variation in the characters being used (Bailey and 'Tupper, 1918; Frost, 1930a, b).

Because of the important influence of these factors on the lengths of fern tracheids, they were taken into consideration when a statistical analysis was made of the relationship between fern tracheid length and taxonomic divergence.

An analysis of tracheid lengths revealed a positive correlation of root tracheid length and relative degree of evolutionary divergence of fern families. Exceptions to this are the Ophioglossaceae and Osmundaceae which have shorter tracheids than expected, and the Marsileaceae which have longer tracheids than expected.

There is a relationship between root tracheid length and other morphological characters within individual families of ferns, but there are also exceptions. In the Ophioglossaceae, the more generalized genus, Botrychium, has shorter tracheids than Ophiglossum, the more advanced genus. In another primitive family, Gleicheniaceae, the correlation between length and relative advancement of the genera is a weak one. In the Marattiaceae, however, the primitive genera do have longer tracheids than the advanced genera. Within moderateiy advanced families, such as Aspidiaceae, rterldaceae and Davalliaceae, the genera which have other primitive characters also tend to have the longest tracheids. The species in the advanced families Polypodiaceae, Vittariaceae, Grammitidaceae and Salviniaceae have shorter tracheids than those in the more primitive families. Here, again, however, Marsileaceae is an exception to the over-all pattern.

In view of the great variation in tracheid length expressed in this survey, it should be recalled that in the ferns we are probably dealing with at least 3 separate major lines of evolution: those of the Ophioglossales, Marattiales and Filicales. There are also wide gaps in our knowledge of the relationships between the numerous fern families and genera within these lines, and some have become so specialized (e.g., Marsileaceae and Salvineaceae) that the general trend in the ferns has been obscured by this extensive specialization. Other factors already discussed, such as ecology, growth habit, and genetic constitution, undoubtedly also contribute to the extensive variability of tracheid length, and strongly reduce the correlation between tracheid length and relative taxonomic position.

\section{LITERATURE CITED}

BaIley, I. W. 1949. Origin of the angiosperms: need for a broadened outlook. Jour. Arnold Arbor. 30: 64-70.

- - 1957. The potentialities and limitations of wood anatomy in the study of the phylogeny and classification of angiosperms. Jour. Arnold Arbor. 38: 243-254.

—_ - and W. W. Tupper. 1918. Size variations in tracheary cells: I. A comparison between the secondary xylems of vascular cryptogams, gymnosperms and angiosperms. Proc. Amer. Acad. Arts Sci. 54: 149-204.

Bierhorst, D. W. 1960. Observations on tracheary elements. Phytomorphology 10(3): 249-305.

Bissett, I. J. W., and H. E. Dadswell. 1950. The variation in cell length within one growth ring of certain angiosperms and gymnosperms. Aust. Forest. 14: $17-29$.

Boodue, L. A. 1904. The structure of the leaves in the bracken fern (Pteridium aquilinum) in relation to environment. Jour. Linn. Soc. Bot. 35: 359-369.

Bower, F. O. 1923. The ferns. Vol. I. Analytical examination of the eriteria of comparisons. University Pıess, Cambridge, Lingland.

- 1926. The ferns. Vol. II. The Eusporangiatae and other relatively primitive ferns. University Press, Cambridge, England.

—_ 1y'z . 'l'he ferns. Vol. III. The leptosporangiate ferns. University Press, Cambridge, England.

Carlquist, S. 1y58. Wood anatomy of Heliantheace (Compositae). 'Lrop. Woods 108: 1-30.

- - 1959. Wood anatomy of Helenieae (Compositae). Trop. Woods 111: 19-39.

- Iyoua. Wood anatomy of Cichorieae (Compositae). Trop. Woods 112: 65-91.

- ly60b. Wood anatomy of the Astereac (Compositae). 'Trop. Woods 11s: 54-84.

Chende, V. I. 1943. Vessel specialization in the late metaxylem of various organs in the Monocotyledonae. Amer. Jour. Bot. 30: 484-490.

Ching, R. C. 1y40. On natural classification of the family "Polypodiaceae." Sunyatsenia 5(4): 201-270.

Christensen, C. 1938. Filicineae. In Fr. Verdoorn, Manual of pteridology. Chapter 20. M. Hijhoff, 'The Hague. 
Copeland, E. B. 1947. Genera filicum. Chronica Botanica, Waltham, Massachusetts.

Diels, L. 1899. Polypodiaceae. In A. Engler and K. Prantl, Die natürlichen Pflanzen Familien I. (Abt. 4) : 139-339.

Dixon, W. J., ANd F. J. Massey. 1957. Introduction to statistical analysis. McGraw-Hill, New York.

Echols, R. M. 1955. Iinear relation of fibrillar angle to tracheid length, and genetic control of tracheid length in slash pine. Trop. Woods 102: 11-22.

Frost, F. H. 1930a. Specialization in secondary xylem of dicotyledons. I. Origins of vessels. Bot. Gaz. 89: $67-94$.

- 1930b. Specialization in secondary xylem of dicotyledons. II. Evolution of end wall of vessel segment. Bot. Gaz. 90: 198-212.

Gould, F. W. 1957. Pollen grain size as related to polyploidy and speciation in the Andropoyon saccharoides $-A$. barbinodes complex. Brittonia 9: 71-75.

Holтtum, R. E. 1949. The classification of ferns. Biol. Rev. 24: $267-296$.

-. 1954. Flora of Malaya. II. Ferns of Malaya. Govt. Printing Office, Singapore.

Jackson, I. W., AND J. T. Greene. 1958. Tracheid length variation and inheritance in slash and loblolly pine. Forest Sci. 4: 316-318.

JefrRey, E. C. 1917. The anatomy of woody plants. Univ. of Chicago Press, Chicago.
Johansen, D. A. 1940. Plant microtechnique. McGraw-Hill, New York.

Morzenti; V. M., AND W. H. Wagner. 1962. Southeastern American "Blackstem spleenworts" of the Asplenium heterochroum-resiliens complex. Assoc. Southeastern Biol. Bull. 9(2): 40-41.

Sierp, H. 1914. Über die Beziehungen zwischen Individuengrösse mit besonderer Berucksichtingung des erblichen Zweigwuchses. Jahrb. Wiss. Bot. 53: $55-124$.

Tippo, O. 1946. The role of wood anatomy in phylogeny. Amer. Midl. Nat. 36: 362-372.

WAGNER, W. H., JR. 1954. The evidence used in recent classifications of the ferns. Huitieme Congr. Internatl. Bot. Rapp. et Commun. au sect. 6: 9-15.

- 1961. Problems in the classification of ferns. Rec. Adv. in Bot. Sec. 9: 841-844.

-2. 1962. The endemic Botrychiums of the southeastern United States. Assoc. Southeastern Biol. Bull. $9: 40$.

WALKER, S. 1961. Cytogenetic studies in the Dryopteris spinulosa complex. II. Amer. Jour. Bot. 48: 607--614.

Whrte, R. A. 1961. Vessels in roots of Marsilea. Science 133: 1073-1074.

. 1962. A comparative study of the tracheary elements of the ferns. Thesis. Univ. of Michigan.

Wherry, E. T. 1961. The fern guide. Doubleday, New York.

\title{
OBSERVATIONS ON THE FINE STRUCTURE OF OEDOGONIUM. II. THE SPERMATOZOID OF O. CARDIACUM ${ }^{1}$
}

\author{
Larry R. Hoffman² and Irene Manton \\ Department of Botany, University of Illinois, Urbana, Illinois \\ and \\ Department of Botany, The University, Leeds, England
}

\begin{abstract}
A B S T R A C T
Hoffman, I. R., and Irene Manton. (U. Leeds, England.) Observations on the fine structure of Oedogonium. II. The spermatozoid of O. cardiacum. Amer. Jour. Bot. 50(5): 455-463. Illus. 1963. - Salient features of the fine structure of the spermatozoid of Oedogonium cardiacum are described and illustrated as they appear in whole mounts and in sections. There is a close resemblance to the zoospore of the same species (Hoffman and Manton, 1962) though the gamete is smaller and in some respects simpler. The flagella, though similar in length to those on the zoospore, are fewer (ca. 30 instead of ca. 120 per cell). The construction of the flagellar ring is similar though there is less mechanical material associated with the flagellar bases in the gamete. Compound "roots" alternating with the flagellar bases are identical in structure and relative position in both types of motile cells; there is no direct connection with the nucleus. Other details of resemblance and difference between the spermatozoid and the zoospore are discussed.
\end{abstract}

Is a PRevious communication (Hoffman and Manton, 1962) the fine structure of zoospores of Oedogonium cardiacum (Hass.) Wittr. was investigated with special reference to salient features of the flagellar apparatus. In the present paper we propose to extend the inquiry to spermatozoids of the same species.

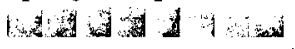

Received for publication September 11, 1962.

2 This work was carried out during tenure of a National Science Foundation Fellowship for the session 1961-62.
The source of motile cells has been exactly as in our previous investigation for which zoospores from male plants grown in soil-water culture were used. The culture (LB39) came originally from the Culture Collection of Algae at Indiana University (Starr, 1960) and the optimum treatment required to produce large numbers of spermatozoids instead of zoospores is as follows. With an old culture (several months old), it is sufficient to transfer a few filaments into a shallow layer 